\title{
REPRESENTAÇÕES SOCIAIS SOBRE O CÂNCER FEMININO: VIVÊNCIA E ATUAÇÃO PROFISSIONAL
}

\author{
Carolina Pasquote Vieira \\ Marcos de Souza Queiroz \\ Universidade Estadual de Campinas
}

RESUMO: Esta pesquisa focaliza o câncer feminino através de duas perspectivas: a proveniente dos profissionais de enfermagem do CAISM-UNICAMP e das pacientes internadas nesta instituição. A proposta do presente trabalho exigiu uma postura metodológica qualitativa, implementada através de entrevistas semi-estruturadas e observação participante. Os dados revelam que construções culturais acerca do diagnóstico da doença induzem a mulher a assumir um papel de doente com implicações radicais em sua rotina de vida. No entanto, o hospital está equipado apenas para o tratamento biológico, relacionado com o corpo físico da paciente. $\mathrm{O}$ aspecto emocional e social da doença é subtraído, o que pode gerar a prestação de uma assistência parcial ao paciente e descontentamento na equipe profissional. Os resultados mostram também que a aproximação mecanicista da doença e da cura ainda é hegemônica no hospital, um aspecto que promove insatisfação tanto nas pacientes como nas profissionais de saúde.

PALAVRAS-CHAVES: câncer; enfermagem; instituição; representações sociais.

\section{SOCIAL REPRESENTATION ABOUT FEMALE CANCER: LIVING EXPERIENCE AND PROFESSIONAL ACTING}

ABSTRACT: This research focuses on female cancer through two perspectives: one that stems from the nursing professionals of CAISM-UNICAMP and other that stems from the patients under treatment at the hospital. The objective of this work required a qualitative methodological approach, implemented through both semi-structured interviews and participant observation. Data show that cultural constructions about disease diagnosis induce women to assume an ill role with radical implications for their everyday life. However, the hospital is equipped to treat only the biological aspects of the patient's physical body. Emotional and social aspects are subtracted - a condition which can generate partial treatment and, at the same time, discontentment among professional staff. Data also show that this aspect promotes dissatisfaction among both patients and the health professionals.

KEYWORDS: cancer; nursing; organization; social representation.

A questão a ser discutida pelo presente artigo refere-se às representações sociais que estão associadas ao câncer feminino, tendo em vista pacientes em tratamento do Centro de Atenção Integral à Saúde da Mulher (CAISM), um órgão da Universidade Estadual de Campinas (Unicamp). Ainda que o estudo se concentre principalmente em mulheres em tratamento neste hospital, ele também se dirige à visão de pessoal de enfermagem desta instituição. A abordagem metodológica deste estudo é essencialmente qualitativa.

A escolha de realização do estudo especificamente com o câncer feminino deve-se ao fato da doença afetar diferentes dimensões da vida da pessoa desse sexo, tanto em nível físico como sociocultural e psíquico. O efeito da doença na mulher é altamente significativo, já que sua constituição feminina fica comprometida após o diagnóstico. O câncer pode ocorrer em diferentes localizações do corpo, mas numa grande proporção, acomete as mamas e os órgãos ginecológicos.

Este estudo parte de uma postura teórica mais ampla que inclui as dimensões socioculturais e psicológicas no entendimento da doença. Nesse sentido, o tratamento de uma doença como o câncer exige medidas que possam contribuir para que a paciente adote uma postura emocional favorável à cura.

O momento em que a mulher se depara com o diagnóstico de câncer, seu modo de vida e suas relações interpessoais passam a ser objetos de reflexão e questionamentos. Considerando que tal processo tem início com a descoberta da doença, torna-se importante atentar para esse momento e realizar uma análise acerca desse tipo de experiência. Trata-se de uma etapa peculiar da vida, no qual a mulher passa a assumir o papel de doente, além de todos aqueles anteriormente desempenhados por ela.

O CAISM é uma instituição que faz parte do complexo da Unicamp. Este centro conta com, aproximadamente, 1.050 funcionários e 136 leitos. Trata-se de uma instituição cuja proposta contempla exclusivamente a mulher, através de uma perspectiva que pressupõe certa abertura em relação à idéia tradicional de doença, que assume apenas o seu aspecto biológico. Adota, nesse sentido, práticas e iniciativas diferenciadas no trabalho com essas pacientes, com a inclusão, ainda que limitada, de dimensões sociais e psicológicas. Tais aspectos, aliados a sua excelência tecnoló- 
gica, faz desse hospital uma referência no tratamento da mulher.

A decisão de incluir nesse estudo um foco dirigido ao pessoal de enfermagem justifica-se pelo fato de que a intensidade da convivência proporcionada tanto pela estadia prolongada como também pelo retorno frequiente das pacientes permite que estas estabeleçam elos mais permanentes com a equipe de enfermagem. Tal aspecto ocorre em contraste com a grande rotatividade no trabalho de médicos e residentes, devido ao fato do CAISM ser um hospitalescola.

A enfermagem é a única especialidade que mantém um membro durante as 24 horas no interior do ambiente hospitalar. Este fato é significativo quando se busca a compreensão de uma patologia como o câncer, que pode contribuir para o surgimento de outras patologias psíquicas, dependendo da forma como for vivenciado, tendo em vista, especificamente, o relacionamento com a equipe de saúde. Nesta perspectiva, os momentos relacionados ao período de internação podem ser determinantes quanto às formas da paciente enfrentar a doença após o recebimento do diagnóstico de câncer.

De um ponto de vista teórico e metodológico mais amplo, $\mathrm{o}$ artigo adota o conceito de representações sociais, conforme desenvolvido por Moscovici (Queiroz, 2003), que procura encontrar, neste conceito, um espaço que correspondesse a um meio termo entre o sociológico e o psicológico. Nesse sentido, as representações sociais podem ser consideradas um conjunto de idéias, saberes e sentimentos incorporados pelos indivíduos, mas que são provenientes de uma estrutura social mais ampla. Portanto, compreendendo-se as representações sociais de diferentes atores, pode-se apreender tanto a essência da realidade social como o nível da personalidade individual que interpreta, manipula e reage às regras e aos valores sociais.

Tal postura é também partilhada pelo método fenomenológico, que busca a essência do fenômeno. O objeto não pode existir sem que o sujeito tenha olhado para ele, por isso a divisão entre sujeito cognoscente e objeto cognoscível torna-se inconsistente. Há, nessa visão, uma perspectiva compreensiva, porque se trata de uma perspectiva que procura conhecer o objeto em suas várias manifestações. As relações e interações entre sujeito e objeto são importantes, e a forma como o sujeito responde é influenciada por esse aspecto. A intenção do pesquisador é parte do experimento, sendo vínculo indissociável entre sujeito e aquele que quer conhecer o objeto (Queiroz, 2003).

\section{Saúde, Doença e Cuidado}

A medicina baseada na ciência moderna consolidou uma concepção de saúde, doença e cuidado que foi historicamente forjada a partir do movimento cultural renascentista e iluminista europeu. Tal referência, que sustenta uma visão de saúde, sempre submetida à questão da doença, leva em consideração apenas os aspectos biológicos da vida do ser humano, relegando a dimensão social, cultural e psicológica do tratamento e da cura. As necessidades e os problemas de saúde neste paradigma passaram a ser solucionados pela ciência e por suas técnicas (Mandú, 2004).

Esta é uma posição referendada pela concepção positivista de ciência moderna em geral, sendo a área da saúde apenas uma delas. No positivismo, há uma completa separação entre sujeito e objeto de pesquisa. Na medicina, essa postura concebe o ser humano como uma máquina e a doença como um mau funcionamento de mecanismos biológicos, o que pressupõe que o ato terapêutico possa ser explicado unicamente pela intervenção física ou química em diferentes partes e estruturas do organismo humano no sentido de eliminar a doença (Queiroz, 2003).

Éneste contexto que a implementação de um paradigma mais abrangente, que inclua as dimensões socioculturais e psicológicas no que se refere à saúde é importante, já que esta abordagem reflete o ser humano como um todo. Esta abordagem compreende o indivíduo em sua subjetividade e em seu contexto sociocultural, atentando para todos os aspectos importantes na apreensão do ser humano. Neste paradigma, corpo e mente são aspectos importantes, e o desenvolvimento de uma patologia está diretamente associada a ambos, observando ainda as demais instâncias da vida. Nesse sentido, o cuidado com a atitude do paciente em relação ao seu problema de saúde aparece como uma dimensão das mais importantes (Queiroz, 2003).

Esta perspectiva é particularmente verdadeira no caso do câncer, uma doença crônico-degenerativa que pressupõe um considerável grau de qualidade na prestação de diversos tipos de serviços que pressupõem vários tipos de cuidado prestados à saúde. A assistência ao paciente oncológico é complexa justamente porque envolve a abordagem de diferentes aspectos da vida do indivíduo: físico, emocional, social, econômico, cultural, espiritual, e também pelos preconceitos e tabus que envolvem a palavra câncer (Costa, Lunardi \& Soares, 2003).

Receber o diagnóstico de câncer pressupõe uma série de conseqüências que atingem diretamente o modo de vida do indivíduo. Algumas delas estão associadas ao aspecto social e familiar; outras, ao psiquismo, como as idéias recorrentes de morte, o medo de mutilação e da perda de algumas pessoas de seu convívio (Ferreira, 1996). A qualidade do cuidado oferecido pelos profissionais de enfermagem tem a ver com a inclusão desse aspecto.

Um serviço abrangente, que inclua esta dimensão, ainda que seja estimulado pela Organização Mundial da Saúde e esteja crescendo em todo o mundo moderno, não é prevalente nos serviços públicos de saúde brasileiros. Além disso, tal postura extrapola a competência do pessoal de enfermagem que, em geral, é treinado principalmente para lidar com o corpo físico e a dimensão biológica do indivíduo. 
A perspectiva da assistência integral à saúde reconhece a importância do contexto, dos processos culturais e familiares, as intersubjetividades, considerando as necessidades e os interesses relacionados com o dia-a-dia dos sujeitos envolvidos. Todos esses aspectos devem ser definidos como pontos de partida e chegada para todas as ações de cuidado individualizado (Mandú, 2004).

Nesse sentido, quando há uma abordagem diferenciada, com vista a uma dimensão mais integrada do indivíduo, a qualidade do serviço de enfermagem varia muito, de acordo com a instituição em que trabalham. As características presentes no atendimento e a forma como o trabalho é desenvolvido são características peculiares de cada local especificamente (Waldow, 1999).

Portanto, ainda que haja um reconhecimento crescente da necessidade de um tipo de cuidado mais abrangente à saúde, poucas instituições adotam esta postura adequadamente. De um modo geral, em uma instituição de saúde pública no Brasil, a disciplina e a ordem imposta pelo paradigma mecanicista são hegemônicas. Os funcionários desse tipo de instituição sofrem, inevitavelmente, uma pressão considerável para exercer a manutenção da ordem, incluindo aqui a exigência de que os pacientes sejam tratados como mecanismos biológicos avariados, despojados de consciência e destituídos de vida emocional.

Nesse contexto, os funcionários influenciam um padrão de comportamento específico entre os pacientes, determinado pelas regras e normas institucionais. Sendo assim, os indivíduos que dependem dos serviços de saúde e estão internados nesse tipo de instituição devem se submeter à cultura organizacional existente. No momento em que se é admitido para entrar em uma instituição hospitalar, a pessoa passa a estar descaracterizada da sua condição de sujeito para tornar-se um objeto aceito que pode ser contabilizado pela administração e pensado como um número para facilitar a rotina do hospital (Goffman, 1999).

A essência de uma instituição é a rotina que rege seu cotidiano. No entanto, esta rotina nem sempre favorece o tratamento de quem é atendido por ela. $\mathrm{O}$ atendimento despersonalizado e impessoal, no interior de uma postura mais ampla que desconsidera as atitudes e os sentimentos do paciente, além de dificultar o convívio social e familiar é amplamente considerado pela literatura como um ambiente desfavorável para a promoção da cura (Arruda \& Marcelino, 1997; Berger \& Luckman, 1987).

Nesse sentido, existe não só o papel do médico, mas também o papel de doente, que muitas vezes implica na perda de liberdade. Ao se comportar de forma diferenciada, o doente sofre pressões sociais no sentido de se conformar com o papel apropriado para a sua condição, dando às instituições médicas a autonomia sobre a sua saúde e seu corpo (Queiroz, 1991).

\section{Métodos e Técnicas}

Os métodos e técnicas básicos utilizados por esta pesquisa foram a observação participante, de acordo com o método antropológico e a realização de entrevistas.

É importante ressaltar que, em uma pesquisa qualitativa, o método é sempre subordinado às perguntas, que vão se desenvolvendo conforme o andamento da pesquisa. Para isso, ele deve ser flexível para acompanhar os desdobramentos provenientes da relação do pesquisador com seu objeto de pesquisa. Em tal contexto, é importante que o pesquisador esteja em campo tanto para conhecer melhor a realidade da pesquisa como para compreender as formas de comportamento e pensamento dos indivíduos pesquisados.

Para a coleta de dados, foram utilizados dois procedimentos fundamentais: a) o procedimento de um diário de campo, no qual as impressões da pesquisadora foram realizadas após cada visita à instituição, de acordo com a tradição legada por Malinowski (1976) e b) áudio-gravação, que permitiu um registro confiável ao qual o pesquisador retorna na medida em que desenvolve suas hipóteses.

O método da observação participante seguiu a tradição antropológica, no interior da qual a realização de um diário de campo surge como um procedimento fundamental. Após cada visita à instituição, a pesquisadora teve o cuidado de escrever suas impressões provenientes do ambiente de pesquisa, incluindo nela conversas informais com outros participantes e hipóteses para futura investigação.

A entrevista semi-estruturada ou semi-dirigida caracteriza-se como um contato face a face com o entrevistado, com o qual se estabelece uma conversação a partir de um roteiro elaborado previamente. Como este roteiro é aberto, ele permite que outras questões não consideradas previamente possam aparecer, em função do desdobramento da entrevista (Ghiglione \& Matalon, 1993).

As entrevistas foram transcritas e organizadas em categorias, a fim de facilitar a análise, de acordo com o método de Análise de Conteúdo, como definido por Bardin (1979). Os dados referentes à observação participante contribuíram para dar um suporte adicional aos dados da entrevista.

Foram entrevistados 12 pacientes internadas na enfermaria da Oncologia do CAISM e 5 membros da equipe de enfermagem responsáveis pela mesma enfermaria. As entrevistas duraram, em média, 2 horas cada uma, tendo sido realizadas no próprio CAISM. Tanto os pacientes como os profissionais foram selecionados aleatoriamente, de acordo com a disponibilidade e interesse na realização do trabalho, não necessitando para isso de nenhum critério definido a priori. O número de indivíduos pesquisados foi determinado pelo critério da saturação.

Apesar de ter sido feito com apenas uma enfermeira, o contato com essa profissional foi legítimo e possibilitou 
a discussão de pontos importantes para a reflexão da presente pesquisa.

Além disso, a observação participante realizada na enfermaria de Oncologia do CAISM deu suporte e ampliou os dados obtidos pelas entrevistas. Durante o período de coleta de dados, algumas horas foram destinadas à observação do local de trabalho das profissionais de enfermagem, dos quartos nos quais as pacientes estavam internadas $\mathrm{e}$ também da relação estabelecida entre ambas.

\section{Discussão}

\section{As Pacientes}

Os relatos demonstraram, em primeiro lugar, que a fase de recebimento do diagnóstico promove uma experiência de desestruturação psíquica, com freqüentes reavaliações sobre relacionamentos interpessoais e atividades anteriormente desempenhadas. As mulheres construíram uma história da doença que adquiriu um significado maior perante a própria história de vida. Revelaram, nesse sentido, aspectos relacionados à evolução da patologia, procedimentos e tratamentos adequados, tornando esses assuntos primordiais em relação àqueles que anteriormente faziam referência ao seu cotidiano. Contudo, a experiência da doença passou a existir em uma esfera íntima, partilhada apenas pelo círculo mais próximo de parentes e amigos, como expressa o trecho de entrevista abaixo:

Não é só por medo de sofrer, eu acho que tem muita gente que não vai te ajudar, que só quer saber de curioso, não vai adiantar nada falar, e pode até passar uma coisa negativa pra mim. Então tem certas pessoas que eu não falo que estou com câncer. Só falo para pessoas que eu confio.

Os dados mostraram também que a vivência do câncer trouxe uma sensação de vazio e sentimento constante de solidão. Tais experiências intensificam-se com a internação, e a mulher faz uso de alguns recursos buscando a diminuição desse sofrimento. A busca pela religião atua positivamente nesse sentido, sendo um apelo externo quando a paciente sente que seus recursos internos são escassos.

Devido a esses fatores, o apego à religiosidade constituiu um aspecto importante extraído das entrevistas. Em tal contexto, a fé adquire a função de estabelecer um pacto com a vida, de conseguir um aliado na luta contra a doença. O objetivo, aqui, é o afastamento da dor e da morte, muitas vezes obtido por promessas. É interessante notar que este tipo de postura foi generalizado entre as mulheres pesquisadas, incluindo até mesmo aquelas que não seguiam uma prática religiosa institucionalizada. $\mathrm{O}$ trecho abaixo dá expressão a esse tema.

Acredito que o tratamento da gente fora os médicos é só Deus, e abaixo de Deus só os médicos. Sou corpo e alma pra Deus... Sempre acreditei, mas estou mais de uns anos pra cá, eu aprendi ler mais a Bíblia...

A formação de vínculos com as companheiras de quarto também atuou positivamente, amenizando sofrimentos referentes à solidão vivenciada no período da internação. As pessoas que faziam parte do contexto hospitalar, em geral, passavam a assumir um lugar significativo na vida dessas mulheres, favorecido pelo processo de identificação com outras experiências de vida.

Converso com todas as pacientes, a gente sempre está conversando... É bom conversar porque a gente está vendo o que o pessoal está passando. Eu fiz muitas amizades com outras pacientes do hospital e isso foi muito bom para mim.

Muitos comportamentos, pensamentos e sentimentos foram modificados durante o processo de internação, e muitos foram determinados pelo mesmo. A ansiedade vivenciada durante a fase de descoberta da doença pôde ser agravada, principalmente durante o período inicial da internação. Tanto a demora de realização de exames, ocasionada pela freqüente quebra de aparelhos necessários para diagnósticos, como a rotatividade da equipe médica do hospital foram temas constantemente mencionados pelas entrevistadas como fonte de aflições e angústias. Como afirmado anteriormente, esse aspecto se faz presente porque o CAISM é um hospital-escola, o que implica em mudança constante de médicos residentes.

A médica que me encaminhou vai estar junto na minha cirurgia, mas eu não sei quem vai fazer a cirurgia. O médico nem veio conversar comigo ainda, eu nem sei que anestesia eu vou tomar ainda.

A internação hospitalar também produziu aflições ocasionadas pela ausência do ambiente familiar. As pacientes internadas preocupavam-se com os filhos, companheiros ou outros diante de uma possível situação de vida onde ela não estivesse mais presente.

Foi possível constatar diferenças qualitativas no relato das pacientes internadas na ala clínica e na ala cirúrgica. As primeiras, provavelmente porque viveram mais experiências de recidiva e têm uma expectativa de cura menor, queixavam-se menos das mudanças ocasionadas em sua rotina diante da internação e mostraram um vínculo maior com a equipe de enfermagem do hospital.

Observou-se nas entrevistas, um sentimento de culpa das pacientes pelo sofrimento dos familiares ocasionado pela doença. Todas as pacientes relataram a necessidade da presença de algum membro de sua família, mas consideraram importante que essa pessoa pudesse oferecer apoio e capacidade de lidar com a situação. Independente do tempo e da causa da internação, avaliaram de forma positiva visitas e telefonemas, mas quando identificavam qualquer sofrimento sentiam-se angustiadas. Isso pode ser 
explicado pela dificuldade que as mulheres com câncer sentem em lidar com sua doença, necessitando de um suporte emocional de seus familiares.

As pacientes entrevistadas com câncer de mama apresentaram algumas características específicas em relação às demais. Aquelas que foram submetidas a mastectomia radical sentiam-se envergonhadas e com receio da rejeição das pessoas, principalmente do companheiro. A diminuição da auto-estima e as modificações corporais começavam a ser sentidas, principalmente, no período pós-operatório. Já as mulheres com mastectomia parcial, preocupavam-se menos com questões relacionadas ao estigma social da doença e com recidivas. Em ambos os casos, eram pacientes mais deprimidas pelo significado simbólico que a mama ocupa no imaginário da mulher.

Eu uso o bojo que eles me deram, mas mesmo assim tem gente que fica olhando. A gente se sente mal com isso, porque a gente sabe que não é da gente, é um bojo que está ali. É difícil olhar no espelho, principalmente nos primeiros dias.

De acordo com Kübler-Ross (1998), há cinco estágios para a elaboração de uma doença terminal: negação, raiva, barganha, depressão e aceitação. Quatro desses estágios puderam ser reconhecidos pelas entrevistas, com a exceção da barganha. Tudo indica que este estágio apresenta poucas condições de se manifestar em contexto de hospital público, onde o poder do paciente diante da estrutura hospitalar, em geral, e do pessoal de saúde, em particular, é muito pequeno. Em um contexto privado ou doméstico, a barganha encontra condições de se manifestar devido ao peso maior conferido à dimensão subjetiva do papel de doente (Kübler-Ross, 1998).

\section{Aceitação}

Eu agradeço a Deus por ter tido meu útero, dei a luz a seis filhas, mas se for para me livrar dessa doença, eu não vou precisar mais dele.

\section{Negação}

Eu achava que era uma glândula inflamada, não achava que era doença. Eu não sabia que eu tinha a doença, porque pra gente, a gente nunca espera, sempre acha que é uma outra coisa. Eu continuo acreditando que não vai ser nada, que vai ser a hérnia de disco.

\section{Depressão}

Ah, não sei, eu sou muito calma, não brigo com ninguém, mas choro muito. Só quando assim, alguma pessoa vem me contar alguma coisa e eu só choro. Eu converso muito pouco, não sou uma pessoa de conversar, eu converso muito pouco, é o meи jeito de ser assim.

\section{Raiva}

...não sei quanto tempo eu vou ter que aturar isso.

\section{As Profissionais}

No que diz respeito às profissionais entrevistadas na pesquisa, verificou-se que, de um modo geral, elas acreditavam em uma proposta de cuidado humanizado e lutavam, através de requisições e reclamações feitas à chefia, pela humanização da prática de enfermagem. Afirmavam a importância dos procedimentos técnicos, mas queixavamse da falta de tempo para executar a prática de uma forma que pudesse incluir maior atenção, principalmente emocional, ao paciente.

Tal constatação foi verificada em todo o pessoal de enfermagem, envolvendo tanto as de nível superior como de nível técnico. Foi constatado, nesse sentido, que as profissionais entrevistadas reconheceram a importância de se levar em conta o estado emocional dos pacientes. Acreditavam que, dessa forma, poderiam exercitar a prática de um cuidado mais humanizado, como expressa o trecho abaixo:

Faz toda a diferença você mostrar que está prestando atenção no lado emocional do paciente e, com isso, você percebe a melhora do seu estado... Por exemplo, você tocar na paciente, pegar na mão dela, conversar com ela e isso é sempre bom.

No entanto, pode-se constatar nas entrevistas que as profissionais estavam desmotivadas, angustiadas e, muitas vezes, pensando em deixar o trabalho, porque não se sentiam ouvidas pela chefia. As dificuldades impostas para a realização das entrevistas demonstraram claramente a concepção de que a profissional de enfermagem está na instituição para executar ações, e não para refletir sobre elas. Mesmo existindo o desejo de estar com a paciente, o cumprimento das tarefas faz com que isso seja muitas vezes difícil de ocorrer.

A gente não tem tempo para conversar com as pacientes, às vezes elas até querem chegar para falar alguma coisa, mas não dá. Às vezes ela te pede alguma explicação, e naquele momento a coisa é tão longa, que não dá tempo.

Relatos referentes ao adoecimento de profissionais fizeram menção a esses dados. A rotina de trabalho é pesada e exige incondicional submissão às regras e expõe as mulheres a situações estressantes. Tal condição é tanto mais verdadeira quanto maior for a posição hierárquica das profissionais da enfermagem. Uma enfermeira tem menos tempo e maior compromisso com as regras do que uma técnica de enfermagem.

Em uma das entrevistas, a técnica de enfermagem admitiu seu dilema em relação à continuidade de seu trabalho no CAISM. Declarou acreditar em um trabalho no qual o profissional tenha espaço para proporcionar qualidade de vida à paciente com câncer, mas afirmou que essa não é uma concepção partilhada por todos os membros de sua 
equipe de trabalho. Relatou um episódio de repreensão por acompanhar uma paciente à sala de exames atendendo a um pedido da mesma.

Nas entrevistas realizadas não foram comuns atitudes como a mencionada acima, nas quais a profissional se expõe e assume a responsabilidade de ser repreendida por atender a um desejo de uma paciente. Isso apenas demonstra que, na maioria dos casos, as profissionais moldam suas ações pela possibilidade de repressão e deixam de praticar a enfermagem na qual acreditam.

No caso da enfermeira de nível superior, as reclamações em relação à rotina de trabalho e às exigências organizacionais foram mais freqüentes, sendo também mais evidente a ansiedade, o estresse e a frustração com o trabalho realizado. Estes dados remetem ao fato de que as enfermeiras têm formação universitária, o que leva a uma reflexão maior sobre suas atividades de rotina e, muitas vezes, a um inconformismo com relação a elas.

As pacientes pedem atenção a toda hora. Quando você chega para falar com elas você se transforma, todo desgaste tem que ficar lá no corredor... você muda num piscar de olhos, é muito interessante, porque você fica pensando, você pensa muito mais no outro do que em você...

Uma queixa generalizada expressa nas entrevistas diz respeito à forma de tratamento dispensada às pacientes. Nesse sentido, as profissionais consideraram que a individualidade das pacientes internadas não é respeitada, suas opiniões não são ouvidas, ou porque há um regimento interno a ser cumprido, ou porque determinados funcionários de plantão são instruídos a executar tarefas em momentos específicos. Atitudes deste tipo podem ser percebidas como um desrespeito, uma invasão na individualidade da paciente, que não está apta a ter preferências quando se encontra internada em uma instituição fechada como o hospital.

Ultimamente eu vou te dizer, que de uns tempos pra cá, não dá tempo. A gente não tem tempo para conversar com as pacientes, às vezes elas até querem chegar para falar alguma coisa, mas não dá. É, porque assim, às vezes ela te pede alguma explicação, $e$ você assim, naquele momento a coisa é tão longa, que não dá tempo.

É contraditório pensar que isso realmente aconteça. As pacientes precisam da presença da equipe de enfermagem, querem conversar, têm uma demanda importante de atenção, estão precisando desse espaço. As profissionais querem estar ao lado dessas pacientes, têm vontade de lutar pela qualidade de vida da mulher portadora de câncer, querem aprender a trabalhar com as questões emocionais presentes no momento de vivência da doença. No entanto, isso não ocorre e nem é permitido ocorrer.
Mesmo que individualmente as profissionais acreditassem na atenção aos aspectos emocionais da paciente, $o$ modelo de trabalho ao qual estavam submetidas não lhes permite efetivar uma prática voltada também para esse aspecto. O paradigma institucional não favorece a realização de ações humanizadas, fazendo com que as funcionárias se limitem ao cumprimento de ordens e regras pré-estabelecidas.

Questões relacionadas à necessidade do apoio emocional ao trabalhador de enfermagem foram freqüentemente encontradas no discurso das mesmas. Lidar com condições de fragilidade das pacientes e administrar as questões institucionais é desgastante para a pessoa inserida nesse tipo de profissão. A cobrança em relação à rotina e às regras institucionais são fortes elementos estressores e podem causar angústias de diferentes ordens. Ao mesmo tempo, as pacientes exigem que $o$ apoio de que necessitam seja fornecido por essas profissionais de forma satisfatória.

Então eu acho que falta essa parte da psicóloga, que é alguém que vai ouvir e não vai contar, e a gente precisa disso como pessoa... A gente está sempre pedindo isso, arrumem uma psicóloga pra gente mesmo que seja uma terapia de grupo. Essas coisas da assistência até que a gente consegue trabalhar muito, eu acho que o que falta, se você tivesse funcionários a mais, essa parte psicológica, você até poderia sentar para conversar um pouco mais com o paciente...

\section{Considerações Finais}

Esta pesquisa estabelece um elo entre as duas categorias de sujeitos focalizados pela pesquisa: os pacientes e os profissionais da enfermagem. Os conteúdos das entrevistas tiveram aspectos comuns e algumas vezes favoreceram a elaboração de categorias de análise que se sobrepuseram. Isso porque o câncer feminino constituiu a realidade vivenciada por todas as mulheres dessa pesquisa, tanto pacientes quanto profissionais.

Além disso, todas estavam presentes em um mesmo contexto de atenção à saúde: o hospital CAISM. É relevante que alguns relatos façam referência a aspectos comuns tais como, por exemplo, a insatisfação em relação ao tratamento do câncer feminino. As pacientes mencionaram a falta de informação prestada pelo pessoal de enfermagem, a dificuldade de se relacionar adequadamente com esse mesmo pessoal, principalmente após a cirurgia, os problemas referentes à rotatividade médica, a falta de seus familiares no período de internação, o apego às companheiras de quarto como alívio de sofrimento. Por outro lado, as profissionais referiram-se ao desejo de exercer uma prática na qual acreditam, à vontade de oferecer uma atenção mais humanizada às pacientes.

$\mathrm{O}$ apego à religiosidade também apareceu nas entrevistas tanto das pacientes como das profissionais. Nas pri- 
meiras, como forma de amenizar o sofrimento da situação vivida, de depositar alguma esperança de cura. Nas últimas, como aceitação da realidade de trabalho, como forma de enfrentamento de um cotidiano de perdas e, finalmente, da luta constante contra a doença. São duas vertentes de um mesmo aspecto, que se complementaram e contribuíram para uma compreensão mais ampla do câncer feminino.

Os dados mostraram que esforços no sentido de melhorar o relacionamento entre pacientes e profissionais da saúde só terão êxito quando aliados às mudanças de condições de trabalho. O período de internação é muito significativo para a mulher portadora de câncer, e pode influenciar positiva ou negativamente todas as fases de desenvolvimento da doença. A forma como a instituição estrutura a rotina de trabalho dos funcionários e o tratamento dos pacientes internados é, por esse mesmo motivo, muito importante no desenvolvimento da cura.

É importante lembrar que um processo de humanização na prestação de cuidado hospitalar passa necessariamente por uma reforma educacional. A formação profissional do enfermeiro, apesar das significativas mudanças na grade curricular que ocorreram nas últimas décadas, ainda é principalmente técnica. $\mathrm{O}$ desejo do contato emocional com o paciente foi encontrado em todas as entrevistas realizadas. Tentativas de ações desse tipo, no entanto, não foram reforçadas. Elas geraram constrangimentos institucionais na atuação do profissional de enfermagem.

A enfermagem está inserida em um paradigma científico que, muitas vezes, não permite que essa dimensão seja focalizada. É necessário que haja uma revolução científica, mas isso não depende nem do ponto de vista do paciente nem do profissional. Trata-se, como mostrou Kuhn (1975), de um grande movimento histórico e cultural que se encontra além do que um indivíduo ou grupo de indivíduos possam fazer isoladamente. Mas mesmo sem poder fazer esse tipo de coisa, as pequenas iniciativas vão se acumulando e um dia elas transbordam em um novo paradigma, talvez, mais humanizado do hospital e do tratamento de câncer (Kuhn, 1975).

As entrevistas mostraram, nesse sentido, vários exemplos de ações que extrapolaram as regras e as rotinas, ao mesmo tempo em que promoveram um contato mais humano entre profissional e paciente. Entre tais ações, houve até mesmo tentativas bem-sucedidas de promoção de reconciliação entre membros familiares.

É possível que a profissional de enfermagem tenha atitudes que consideram os aspectos emocionais das pacientes mesmo trabalhando em uma instituição na qual tal aspecto não é privilegiado. No entanto, em um contexto que passe a privilegiar este aspecto como fundamental à promoção da saúde, é preciso que haja um treinamento profis- sional específico e abrangente. Se aspectos humanizados forem realmente importantes para o cuidado e promoção de cura, como várias investigações científicas demonstram, é fundamental que iniciativas nesse sentido passem a ser orientadas por uma aproximação menos voluntarista e mais científica.

Para finalizar este trabalho, gostaria de mencionar que o CAISM tem instituído, pouco a pouco, o cuidado psicológico em outros setores de seu atendimento como, por exemplo, na área de aconselhamento genético. Vimos que o pessoal de enfermagem reivindica explicitamente a inclusão de tal tipo de atenção voltada ao cuidado relacionado ao câncer feminino. Como também os usuários do serviço solicitam uma atenção mais humanizada, é provável que, quando for instituído, esse tipo de aproximação encontrará um campo favorável para ser implementado. Em sintonia com várias fontes teóricas mencionadas na introdução deste trabalho, a inclusão de tal tipo de cuidado pode, de fato, vir a ser uma importante melhora no serviço de atenção ao câncer feminino.

\section{Referências}

Arruda, E.N. \& Marcelino, S.R. (1997). Cuidando e confortando. In: Nascimento-Schulze, C.M. (1997) Dimensões da dor no câncer: reflexões sobre o cuidado interdisciplinar e um novo paradigma de saúde (pp.1567-189). São Paulo: Robe.

Bardin, L. (1979) Análise de Conteúdo. Lisboa: Edições 70.

Berger, P.L. \& Luckman, T. (1987). A construção social da realidade ( $7^{\mathrm{a}}$ ed.). Petrópolis: Vozes.

Costa, C., Lunardi Filho, W.D. \& Soares, N.V. (2003). Assistência humanizada ao cliente oncológico: reflexões junto à equipe. $R e-$ vista Brasileira de Enfermagem, 56, 310-314.

Ferreira, N.M.L.A. (1996). O câncer e o doente oncológico segundo a visão de enfermeiros. Revista Brasileira de Cancerologia, 42, 161-170.

Ghiglione, R. \& Matalon, B. (1993). O inquérito: teoria e prática. Portugal: Celta.

Goffman, E. (1961). Manicômios, prisões e conventos. São Paulo: Perspectiva.

Kübler-Ross, E. (1998). Sobre a morte e o morrer: o que os doentes terminais têm a ensinar a médicos, enfermeiras, religiosos e aos seus próprios parentes ( $8^{\mathrm{a}}$ ed.). São Paulo: Martins Fontes.

Kuhn, T.S. (1975). A estrutura das revoluções científicas. São Paulo: Perspectiva.

Malinowski, B. (1976). Argonautas do Pacífico Ocidental. São Paulo: Abril Cultural.

Mandú, E.N.T. (2004). Intersubjetividade na qualificação do cuidado em saúde. Revista Latino-Americana de Enfermagem, 12(4), 665-675.

Queiroz, M.S. (1991). Perspectivas teóricas sobre medicina e profissão médica: uma proposta de enfoque antropológico. Revista de Saúde Pública, 25, 318-325.

Queiroz, M.S. (2003). Saúde e doença: um enfoque antropológico. Bauru: Edusc.

Waldow, V.R. (1999). Cuidado humano: o resgate necessário. Porto Alegre: Sagra Luzzatto. 
Vieira, C.P. \& Queiroz, M.S. "Representações Sociais sobre o Câncer Feminino: Vivência e Atuação Profissional"

Carolina Pasquote Vieira é Psicóloga, Mestre em Enfermagem pela Universidade Estadual de Campinas. Endereço: Rua Professor Oscar Alves Janeiro, 133, Jardim das Flores, Araras, SP, 13607216. ninapvieira@bol.com.br

Marcos de Souza Queiroz é Doutor pela Universidade de Manchester, Inglaterra. Pesquisador do Centro de Memória e Professor dos Programas de Saúde Mental e Enfermagem pela Faculdade de Ciências Médicas da Unicamp. msq44@uol.com.br

Esta pesquisa contou com apoio financeiro da CAPES.
Representações sociais sobre o câncer feminino: vivência e atuação profissional

Carolina Pasquote Vieira e Marcos de Souza Queiroz Recebido: 07/07/2005

$1^{\text {a }}$ versão reformulada: 09/03/2006

Aceite final: 10/03/2006 